\title{
FEMALE-PREDOMINANT SEX RATIOS IN ANGIOSPERMS
}

\author{
DAVID G. LLOYD \\ Botany Department, University of Canterbury, Christchurch, \\ New Zealand
}

Received 3.i.73

\section{Summary}

\begin{abstract}
A model is presented which expresses the seed production of dioecious and gynodioecious animal-pollinated Angiosperms in terms of the relative seedfecundity of the sexes, the number of pollinator visits to each flower and the sex ratio. The model predicts that the maximum seed set occurs when females predominate, providing the pollinators visit each flower more than once and the seed set of males is not high.

There is strong evidence that a marked preponderance of females in species of four genera is due to more frequent fertilisation by female-determining pollen nuclei than by male-determining nuclei. Two hypotheses have been proposed to explain this differential fertilisation.

Several objections are raised to the hypothesis of Lewis (1942), Mulcahy (1967) and Kaplan (1972) that female-predominant sex ratios have been selected because they maximise the total seed production of populations. It is considered that the hypothesis of Smith (1963) that the differential fertilisation is a consequence of the genetic differentiation of sex chromosomes offers a more likely explanation of female-predominant sex ratios.
\end{abstract}

\section{INTRODUCTION}

Female plants have been reported to be more numerous than male plants in one or more natural populations of dioecious Angiosperm species belonging to at least eight genera (Lewis, 1942 lists earlier counts; Smith, 1963 and 1968; Zuk, 1963; Elkington and Woodell, 1963; Godley, 1964; Mulcahy, 1967; Putwain and Harper, 1972). In four of these genera, viz. Silene, Rumex, Cannabis and Humulus, there is experimental evidence that the immediate cause of the unequal ratios is more frequent fertilisation of ovules by female-determining pollen nuclei than by male-determining nuclei (reviewed in Allen, 1940 and Godley, 1964). Correns (1928 and earlier) found in Silene alba (= Melandrium album) and Rumex acetosa that higher frequencies of females resulted when large amounts of pollen were placed on the stigmas than when small amounts of pollen were used. From these and other experiments, Correns proposed that the female-determining pollen tubes reached the ovules sooner on the average than the male-determining pollen tubes, either through earlier germination or faster growth or both. He suggested that the increased success of male-determining pollen following sparse pollination was due to reduced competition under these conditions. An increase in the amount of pollen used also results in an increase in the proportion of female progeny in Cannabis sativa (Riede, 1925) and Humulus japonicus (Kihara and Hirayoshi, 1932, from Allen, 1940 and Godley, 1964), two other species with more numerous females. The observation that the predominance of females is already present in young seedlings in Rumex hastatulus (Smith, 1963) and Rumex thyrsiflorus (Zuk, 1963) is consistent with differential fertilisation in these species also. 
Several authors have commented on the possible selective advantage of differential fertilisation in favour of female-determining nuclei. Lewis (1942) reasoned that if males were in excess of the numbers necessary for the full fertilisation of females, the competition between pollen would result in Y-carrying pollen being less successful. The number of males would be reduced until sparser pollinations caused the competition effect to vanish. Lewis suggested that the pollen competition provided a means of adjustment of the sex ratio to the reproductive economy of the population. Mulcahy (1967) examined the seed set in five experimental populations of Silene alba with different ratios of male and female flowers. He found that the highest total seed set occurred at flower ratios which corresponded to even more numerous female plants than in natural populations. Mulcahy proposed that the female-predominant ratios deviated from equality towards the optimal ratio resulting in the highest seed production and "were of positive selective value to the species". Kaplan (1972) introduced a theoretical model which predicts the sex ratio producing the greatest total seed set in uniovulate wind-pollinated species. Maximum seed production is obtained with more numerous females at higher plant densities and with approximate equality of the sexes at lower densities.

An alternative explanation of differential gamete success was proposed by Smith (1963). In Rumex hastatulus, the Y1 and Y2 chromosomes lack genes which are essential for diploid development. Smith suggested that the genetic inefficiency of the $\mathrm{Y}$ chromosomes may also be expressed in the gametophyte generation, causing the $\mathrm{A}+\mathrm{X}$ gametophytes to be more vigorous and have a selective advantage over $\mathrm{A}+\mathrm{Y} 1+\mathrm{Y} 2$ gametophytes. This hypothesis assumes that differential fertilisation is not directly selected for, but is a secondary consequence of the differentiation of $\mathrm{X}$ and $\mathrm{Y}$ chromosomes.

The model presented below describes the seed set in animal-pollinated dioecious and gynodioecious Angiosperms in terms of the sex ratio, the number of insect visits and the relative seed contributions of the sexes. Following this, the ability of the various hypotheses to explain the distribution of female-predominant sex ratios is examined.

\section{Total SEED SET IN DIOECIOUS AND GYNODIOECIOUS ANIMAL-POLLINATED} ANGIOSPERMS

The polleniferous plants of both dioecious and gynodioecious populations are referred to as males, as in Lloyd $(1973 b)$. The model assumes that all female plants bear the same number of ovules, $O$, and produce no pollen and that all males produce the same amount of pollen. In gynodioecious populations males produce some offspring from seed: the quantity of seed is measured by the relative seed fecundity, $F$, the number of offspring produced via seed by each male divided by the number produced by each female, i.e. $1 \geqq F>0$ (Lloyd, 1973b). In dioecious populations, males produce no seed, i.e. $F=0$. The proportion of females is $p$; the proportion of males is $1-p$. The number of breeding individuals in the population is $\mathcal{N}$. It is assumed that the ovules of male plants are invariably fertilised, by either self- or cross-pollination.

If every flower of female plants is visited one or more $(x)$ times, the 
probability of an ovule of a female plant being fertilised is $1-p^{x}$ (Lloyd, $1973 b)$. Then, the total seed set of the population,

$$
\begin{aligned}
R & =\text { seed set on females plus seed set on males } \\
& =O \mathcal{N}\left[\left(1-p^{x}\right) p+F(1-p)\right] \\
& =O \mathcal{N}\left[-p^{x+1}+(1-F) p+F\right]
\end{aligned}
$$

The rate of change of $R$ with change in $p$,

$$
\frac{d R}{d p}=O \mathcal{N}\left[-(x+1) p^{x}+1-F\right]
$$

$R$ has a single maximum value when $\frac{d R}{d p}=0$, i.e.

$$
(x+1) p^{x}=1-F
$$

where $p_{m}$ is the proportion of females resulting in the maximum total number of seeds, i.e.

$$
p_{m}=\left(\frac{1-F}{1+x}\right)^{\frac{1}{x}}
$$

When the number of pollinator visits is fewer than one to each flower, a fraction $x^{\prime}$ of the flowers is considered to be visited once only. The probability that an ovule of a female plant is fertilised is then $x^{\prime}(1-p)$ (Lloyd, 1973b). Then,

$$
\begin{aligned}
R & =O \mathcal{N}\left[x^{\prime}(1-p) p+F(1-p)\right] \\
& =O \mathcal{N}\left[-x^{\prime} p^{2}+\left(x^{\prime}-F\right) p+F\right] \\
\frac{d R}{d p} & =O \mathcal{N}\left[-2 x^{\prime} p+x^{\prime}-F\right] .
\end{aligned}
$$

The maximum value of $R$ occurs when $\frac{d R}{d p}=0$, i.e.

$$
p_{m}=\frac{x^{\prime}-F}{2 x^{\prime}}
$$

The female frequencies at which most seeds are produced, calculated from equations (1) and (2) for particular values of $x$ or $x^{\prime}$ and $F$, are shown in table 1 and fig. 1. If males are as fecund as females $(F=1)$, then $p_{m}=0$. If males are even slightly less fecund than females $(F>1)$, the maximum seed set occurs when there is a proportion of females in the population, providing there is at least one pollinator visit to each flower. If only a fraction of flowers is visited, the maximum seed set is obtained without females unless the relative seed fecundity drops below the particular fraction of flowers visited.

For all values of relative seed fecundity below one, $p_{m}$ increases as the number of pollinator visits increases. When the number of visits is infinite and all ovules of female plants are fertilised, $p_{m}$ equals one for all values of $F$ less than one. But an all-female population is impossible, since there would be no pollen produced, and the greatest seed set would in practice be obtained with a high proportion of females.

If the number of pollinator visits is finite, the maximum seed set in gynodioecious populations ( $1 \geqq F>0$ ) occurs when there is a predominance of 
TABLE 1

Frequencies of female plants at which the maximum total seed set occurs

Number of visits to each flower*

Infinite

10

3

2

1

$\frac{1}{2}$

$\frac{1}{4}$

Female frequencies, $p_{m}$, at various values of relative seed fecundity, F

$\begin{array}{lcccccc}\begin{array}{c}\text { General } \\ \text { formula } \\ 1\end{array} & F=0 & F=0.25 & F=0.50 & F=0.75 & F=0.90 & F=1.0 \\ \left(\frac{1-F}{11}\right)^{\frac{1}{10}} & 1 & 1 & 1 & 1 & 1 & 1 \\ \left(\frac{1-F}{4}\right)^{\frac{1}{3}} & 0.79 & 0.76 & 0.73 & 0.69 & 0.62 & 0 \\ \left(\frac{1-F}{3}\right)^{\frac{1}{2}} & 0.63 & 0.57 & 0.50 & 0.40 & 0.29 & 0 \\ \frac{1-F}{2} & 0.58 & 0.50 & 0.41 & 0.29 & 0.18 & 0 \\ \frac{1-2 F}{2} & 0.50 & 0.38 & 0.25 & 0.13 & 0.05 & 0 \\ \frac{1-4 F}{2} & 0.50 & 0.25 & 0 & 0 & 0 & 0\end{array}$

* Fractional values mean that a given fraction of flowers is visited once only, the remainder are not visited.

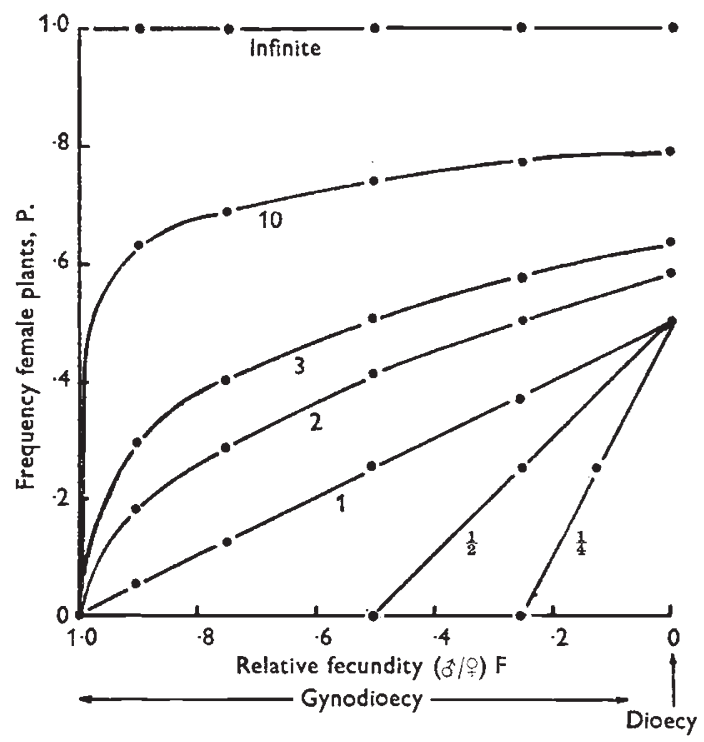

Fig. 1.- The relationship between the relative seed fecundity, $F$, and the frequency of female plants producing the highest total seed in a population, $p_{m}$, for various numbers of pollinator visits to every flower--shown beside each curve.

females, providing there is more than one visit to each flower and the male fecundity is not too high (fig. 1). In dioecious populations, equal numbers of males and females give the highest seed set if only a fraction of the flowers are visited; as the number of visits increases beyond one, the sex ratio producing 
the most seeds is one of increasing female predominance. On this model, a predominance of males does not produce the highest seed set in a dioecious population at any level of pollinator activity.

\section{Discussion}

Two aspects of female predominance in dioecious Angiosperms will be considered in turn:

1. The mechanism directly causing the deviations from equality.

2. The selective value of the deviations, either to individuals within a population or to the populations themselves.

If the male is the heterogametic sex in a dioecious species, unequal sex ratios may be directly due to either differential success of male- and femaledetermining gametes or to differential survival of the sexes at any stage from zygote formation to reproductive maturity (Lloyd, 1973b). In the species of six of the genera* in which female-predominant populations have been reported, the males are known to be the heterogametic sex (Westergaard, 1958). In four genera, viz., Silene, Rumex, Humulus and Cannabis, there is strong evidence that the excess of females is due to gamete selection, as outlined in the introduction. Female proportions higher than 55 per cent have been reported in all four genera (Lewis, 1942; Smith, 1963; Zuk, 1963; Mulcahy, 1967; Putwain and Harper, 1972). The immediate causes of the less pronounced female predominance (females between 50 and 55 per cent; Lewis, 1942) in Spinacia oleracea and Mercurialis annua are not known.

If the ratio of success of male-determining pollen nuclei to that of femaledetermining nuclei is $G$ and the proportion of females in the populations is $p$, then $G=(1-p) / p$ (Lloyd, 1973b). The highest recorded proportion of females in natural populations of dioecious Angiosperms occurs in Rumex arifolius (an average of $92 \cdot 8$ per cent females; Zuk, 1963). Assuming that the unequal sex ratio in $R$. arifolius is due to selective fertilisation, $G=0.072 / 0.928=0.078$, i.e. male-determining nuclei succeed less than one-twelfth as often as female-determining nuclei. The lower proportions of females in the other species may be explained by a less extreme difference in the success rates of the two types of pollen nuclei.

The adaptive significance of female-predominant sex ratios is less certain than the immediate cause. Lewis (1942) and Mulcahy (1967) have postulated that such ratios maximise the total seed production of the populations. The theoretical model of Kaplan (1972) for wind-pollinated populations and the calculations above for animal-pollinated species confirm the verbal arguments of Lewis and Mulcahy that the greatest seed production in a population occurs with a preponderance of females, provided that the

* In the seventh genus, Aciphylla, Godley (1964) reported a significant excess of females in two populations of $A$. aurea. It is not yet known which sex is heterogametic in Aciphylla. The present author has since reported that male-predominance is characteristic of Aciphylla and closely related sexually dimorphic Umbelliferae (Lloyd (1973a). The breeding systems of these Umbelliferae are currently being studied by $\mathrm{Mr} \mathrm{G}$. J. Webb, so the female-predominant Aciphylla populations will not be considered further here. In the eighth genus, Potentilla, some populations of $P$. fruticosa have a predominance of females; other populations have more numerous males (Elkington and Woodell, 1963). The female sex is heterogametic in $P$. fruticosa (Grewal and Ellis, 1972) and the cause of the unequal ratios is unknown. 
pollination conditions are favourable. Moreover, Mulcahy (1967) has shown experimentally that in Silene alba the highest seed set is obtained with a considerable excess of female plants.

Before the "maximum seed set hypothesis" can be accepted, however, a plausible suggestion as to the way in which sex ratios maximising seed production have been selected is required. The hypotheses of Lewis, Mulcahy and Kaplan postulate that the seed set of the whole population is maximised. This implies, although it was not explicitly stated in any of the three papers, that selection operates between populations rather than between individuals of a population. But there are several serious difficulties concerning the direction and efficacy of group selection operating on total seed production. First, it cannot be assumed that the maximisation of seed set is automatically advantageous to a population. In perennial polycarpic species, for example, the resources available to the plants in any one year are apportioned between current reproduction and vegetative growth and maintenance allowing reproduction in subsequent years. The optimal allocation of resources may result in a lower seed set than the maximum possible value. Mulcahy (1967) noted also that a greater seed set may lower the quality of the seed produced.

Even if the maximum seed set is advantageous to a population, it is doubtful whether group selection can achieve this maximum. Fisher (1930) pointed out that natural selection tends to equalise parental expenditure on male and female offspring. Since male and female seeds of dioecious Angiosperm species are, as far as known, similar or identical in the rates of mortality and of utilisation of parental resources, individual selection will favour approximate equality of the sexes in the seeds. And apart from considerations of post-zygotic parental expenditure, the equal reproductive value of males and females causes individual selection to favour equality of the sexes at reproduction (Shaw and Mohler, 1953). If group selection is to maintain sex ratios producing the maximum seed set, it is therefore necessary to explain how the alleles causing deviant ratios persist in populations in which individual selection favours equality of the sexes. The operation of group selection requires either the replacement or infiltration of populations with non-optimal sex ratios by other populations with ratios closer to the optimal value or else a greater rate of establishment of daughter populations by populations closer to the optimal ratio. The selection of populations is necessarily much slower than that of individuals within a population. It is difficult to see how intermittent group selection could maintain sex ratios at a value maximising the seed production when it is opposed by individual selection operating every generation.

The hypotheses of Lewis (1942) and Mulcahy (1967) contain an additional proposition, which is really a subsidiary hypothesis, although Lewis gave it greater emphasis than selection of the populations. He proposed that gamete selection in favour of female-determining pollen enables a population to adjust its sex ratio towards the optimal value. He reasoned that "an excessive number of male plants in the population will supply the condition necessary for competition between pollen, and consequently fewer Y-carrying than $\mathrm{X}$-carrying pollen grains will fertilise the eggs, thus producing more females in the next generation. As soon as the number of males in the population is reduced below the optimum, the pollination will be sparse and the competition effect will vanish."

It seems unlikely that gamete selection can effectively adjust sex ratios to 
closely approach the diverse values giving maximum seed set under different conditions. The postulated adjustment of the sex ratio requires a strong correlation between the abundance of male plants and the intensity of pollen competition. This in turn demands rather restrictive pollination conditions. If the pollinators are efficient, a single visit may saturate a stigma with pollen. If the pollinators are inefficient, a number of visits may be required to saturate a stigma, but this number will be closely related to the intensity of pollen competition only if the visits occur within a short time interval. Any correlation will be further weakened by temporal and spatial variation in the habitat, weather and insect abundance and behaviour (cf. Grodley, 1964). These complications are illustrated by the lack of a clear relationship between the $\hat{\sigma}$ : $ᄋ$ flower ratio and the sex proportions among the progeny in the experiments conducted by Mulcahy (1967) with Silene alba. Of the 15 progeny families he obtained, only two, from parents ranked fourth and eleventh in $\delta$ : o flower ratios, produced an excess of females. The prospects of an overall correlation between male abundance and pollen competition are still poorer in the genera other than Silene in which female-predominant sex ratios are known. These genera all have only one or two ovules per flower (whereas Silene has several hundred), so even a single visit from an inefficient pollinator could result in severe pollen competition.

Another observation that is difficult to explain as an optimal adjustment of the sex ratio is the slight excess of female offspring which is sometimes observed even with sparse pollinations (Allen, 1940). If this occurred in nature, females would continue to be produced in excess, regardless of how rare males were.

A final objection to the maximum seed set hypothesis is that it does not adequately explain the limited occurrence and the distribution of femalepredominant ratios in sexually dimorphic plants. The calculations given above show that in gynodioecious populations female-predominant ratios produce the highest total seed set, provided pollinator visits are at least moderately frequent and the seed set on males is not high. But the majority of sex ratio counts of gynodioecious populations have revealed a predominance of males. Occasional counts of gynodioecious populations show an excess of females (Burrows, 1960; Connor, 1965; Ross, 1969; Valdeyron et al., 1970; Lloyd, 1973a), but a significant overall excess of females is not known in any gynodioecious species. Among dioecious species, female-predominent ratios also produce the highest seed set in both wind-pollinated (Kaplan, 1972) and animal-pollinated species (above) if pollination conditions are favourable. The instances of female predominance in dioecious species are, however, outnumbered by those of male predominance (Godley, 1964; Lloyd, 1973a).

An alternative hypothesis of the origin of the competitive superiority of female-determining pollen and the resulting excess of females has been proposed by Smith (1963). He pointed out that if the genetic inefficiency of the $\mathrm{Y}$ chromosomes which is evident in the sporophytes of Rumex hastatulus was also expressed in the gametophyte generation, male-determining pollen would be competitively inferior to female-determining pollen. Mulcahy (1971) found a correlation between a gametophytic character, relative speed of pollen tube growth, and a sporophytic character, relative seed weight, in Zea mays. Smith's hypothesis does not require group selection or even a direct advantage to individuals within a population, but supposes instead 
that the gamete selection is a consequence of the accumulation of nonfunctional genes in the normally hemizygous $\mathrm{Y}$ chromosomes of dioecious species. The " sex chromosome differentiation hypothesis" readily explains the greater proportions of females observed under the competitive conditions of heavy pollination as well as the persistence of slight male deficiencies after sparse pollination in some trials. Moreover, the production of seed by the males of gynodioecious species ensures that both chromosomes carrying the sex loci are frequently homozygous. This is likely to prevent the accumulation of non-functional loci and hence the appearance of a female bias in gynodioecious species.

The well-known tendency for $\mathrm{Y}$ chromosomes to be genetically inert is not uniformly expressed in dioecious species (Westergaard, 1958; Dronamraju, 1965). If genetic differences between $X$ and $Y$ chromosomes are the cause of female-predominant sex ratios, we might expect a relationship between the occurrence of such ratios and the degree of differentiation of the sex chromosomes. A relationship of this kind appears to be present, although the number of species with known female predominance is small. The eight species (excluding Aciphylla aurea and Potentilla fruticosa) in which more than 55 per cent females have been reported in natural populations (Lewis, 1942; Smith, 1963; Zuk, 1963; Mulcahy, 1967; Putwain and Harper, 1972), include all the species in which there is evidence for gamete selection. It is striking that the four genera involved-Rumex, Silene, Humulus and Cannabisare the only known genera of dioecious Angiosperms which have both heteromorphic sex chromosomes and inviable YY genotypes (Westergaard, 1958; Williams, 1964). That is, marked female predominance is confined to exactly those four genera in which the differentiation of sex chromosomes is most advanced on combined cytological and genetical criteria. In contrast, the two dioecious species with less marked female predominance, Spinacia oleracea and Mercurialis annua, have viable YY plants and lack heteromorphic chromosomes (Westergaard, loc. cit.; Williams, loc. cit.).

One dioecious species group, Rumex subgenus Acetosella, may have heteromorphic sex chromosomes and also inviable YY genotypes (Löve, 1943; Westergaard, 1958; Singh and Smith, 1971) and yet the males approximately equal or slightly exceed the females in number (Löve, 1943; Harris, 1968; Putwain and Harper, 1972). In sugbenus Acetosella, the heteromorphy of the sex chromosomes, if present, is less pronounced than in the female-predominant Rumex species of subgenus Acetosa and the Y chromosome has a strong male-determining role lacking in the latter species. The genetic inefficiency of the $\mathrm{Y}$ chromosome is therefore probably less in sg. Acetosella. The sex ratio in $R$. acetosella is also complicated by differential survival of the sexes (Harris, 1968; Putwain and Harper, 1972).

The suggested relationship between the development of femalepredominant sex ratios and the degree of differentiation of the sex chromosomes is likely to be complex. The measures of X-Y differentiation are not always in agreement. For example, Carica papaya has an inviable YY genotype but lacks heteromorphic sex chromosomes, whereas Asparagus officinalis has viable YY plants and heteromorphic sex chromosomes (Williams, 1964). A number of factors influence the tendency towards genetic inertness of Y chromosomes. Nei (1970) has shown that the accumulation of nonfunctional genes on $\mathrm{Y}$ chromosome is influenced by the effective population size and the heterozygous effect of non-functional mutations as well as by the 
recombination frequency between the non-functional and sex-determining loci. Moreover, the accumulation of various non-functional alleles need not invariably affect the function of the haploid gametophyte and hence the sex ratio. The degree of correlation between the inertness of YY diploids and the selective disadvantage of $\mathrm{Y}$ gametophytes will depend on the extent to which the genes affecting sporophyte development also function in the gametophyte. The complexity of gamete selection resulting in femalepredominant sex ratios is shown by the demonstration by Correns (1928) and Lawrence (1963) that in Silene alba (= Melandrium album) the genotype of different males (and to a less extent of females also) affects experimental sex ratios.

Żuk (1970) proposed that differential fertilisation in Rumexflthyrsiflorus, which like $R$. hastatulus has XYY males and XX females, is caused by the presence of two $\mathrm{Y}$ chromosomes in male-determining gametes, rather than the absence of $\mathrm{X}$ chromosomes. He performed crosses with exceptional XYYYY males, which he assumed produce equal numbers of male- (YY) and female-determining (XYY) gametes. The progeny consisted of approximately equal numbers of males and females. Żuk suggested that the significant factor in sex-chromosome differentiation in $R$. thyrsiflorus may be the extra DNA in male gametes.

It is apparent that we are far from a full understanding of all factors influencing the production of female-predominant sex ratios. Nevertheless, it seems to the present author that the evidence available to date is in better agreement with the "sex chromosome differentiation hypothesis" than with the " maximum seed set hypothesis" of Lewis (1942), Mulcahy (1967) and Kaplan (1972).

Acknowledgment.-I am grateful to Dr M. D. Ross for critical comments on a draft of the manuscript.

\section{REFERENCES}

ALlen, C. E. 1940. The genotypic basis of sex-expression in Angiosperms. Bot. Rev., 6, 227.300 .

Burrows, c. J. 1960. Studies in Pimelea. I. The breeding system. Trans. Roy. Soc. New Zealand, 88, 29-45.

CONNOR, H. E. 1965. Breeding systems in New Zealand grasses. V. Naturalised species of Cortaderia. New Zealand 7. Bot., 3, 17-23.

CORRENS, c. 1928. Bestimmung, Vererbung und Verteilung des Geschlechtes bei den höheren Pflanzen. Handb. Vererbungsw., 2, 1-138.

Dronamraju, $K$. R. 1965. The function of the $Y$ chromosome in man, animals and plants. Adv. Genet., 13, 227-310.

elkington, T. T., AND WOODEll, s. R. J. 1963. Potentilla fruticosa L. (Dasiphora fruticosa (L.) Rydb.). 7. Ecology, 51, 769-781.

FISHER, R. A. 1930. The Genetical Theory of Natural Selection. Oxford University Press, Oxford.

GODLEY, E. J. 1964. Breeding systems in New Zealand plants. 3. Sex ratios in some natural populations. New Zealand 7. Bot., 2, 205-212.

grewal, M. S., AND ellis, J. R. 1972. Sex determination in Potentilla fruticosa. Heredity, 29, 359-362.

HARRIs, w. 1968. Environmental effects on the sex ratio of Rumex acetosella L. Proc. New Zealand Ecol. Soc., 15, 51-54.

xaplan, s. M. 1972. Seed production and sex ratio in anemophilous plants. Heredity, 28, 281-285.

KIHARA, H., AND hiRAYOShI, I. 1932. Die Geschlechtschromosomen von Humulus japonicus Sieb. et Zucc. 8th Congr. Jap. Ass. Adv. Sci., 363-367.

LAWRENCE, C. W. 1963. Genetic studies on wild populations of Melandrium. II. Flowering time and plant weight. Heredity, 18, 149-163. 
LEWIs, D. 1942. The evolution of sex in flowering plants. Cambr. Phil. Soc. Biol. Rev., 17, $46-67$.

LÖVE, A. 1943. Cytogenetic studies on Rumex subgenus Acetosella. Hereditas, 30, 1-136.

LLOYD, D. G. 1973a. Sex ratios in sexually dimorphic Umbelliferae. Heredity (in press).

LLOYD, D. G. 1973b. Theoretical sex ratios of dioecious and gynodioecious Angiosperms. Heredity, 31, 11-34.

MULCAHY, D. L. 1967. Optimal sex ratio in Silene alba. Heredity, 22, 411-423.

MULCAHY, D. L. 1971. A correlation between gametophytic and sporophytic characteristics in Zea mays L. Science, 171, 1155-1156.

NEI, M. 1970. Accumulation of non-functional genes on sheltered chromosomes. Amer. Nat., 104, 311-322.

PUTWAIN, P. D., AND HARPER, J. L. 1972. Studies in the dynamics of plant populations. V. Mechanisms governing the sex ratio in Rumex acetosa and R. acetosella. F. Ecol., 60, 113-129.

RIEDE, w. 1925. Beitrage zum Geschlechts- und Anpassungs-problem. Flora, 18/19, $421-452$.

Ross, M. D. 1969. Digenic inheritance of male sterility in Plantago lanceolata. Can. F. Genet. Cytol., 11, 739-744.

SHAw, R. F., AND mohler, J. D. 1953. The selective significance of the sex ratio. Amer. Nat., 87, 337-342.

SINGH, R. B., AND SMITH, B. w. 1971. The mechanism of sex determination in Rumex acetosella. Theor. Appl. Genetics, 41, 360-364.

smrth, B. w. 1963. The mechanism of sex determination in Rumex hastatulus. Genetics, 48, 1265-1288.

VALDEYRON, G., ASSOUAD, W., AND DOMMÉE, B. 1970. Coéxistence des determinismes génique et cytoplasmique de la stérilité mâle: recherche d'une hypothèse explicative. In Symposium Stérilité Mâle en Horticulture, Versailles.

WESTERGAARD, M. 1958. The mechanism of sex determination in dioecious flowering plants. Adv. Genet., 9, 217-281.

williams, w. 1964. Genetical principles and plant breeding. Blackwell, Oxford.

żUK, J. 1963. An investigation on polyploidy and sex determination within the genus Rumex. Acta Soc. Bot. Polon., 32, 5-67.

żuk, J. 1970. Function of $\mathrm{Y}$ chromosomes in Rumex thyrsiforus. Theor. Appl. Genetics, 40, 124-129. 